\title{
Estimation of the Daily Global Solar Radiation using RadEst 3.00 Software at Nepalgunj, Nepal
}

\author{
${ }^{1}$ Bed Raj KC, ${ }^{2}$ Shekhar Gurung \\ ${ }^{1}$ Mahendra Multiple Campus, Tribhuvan University, Nepalganj, Nepal \\ ${ }^{2}$ Central Department of Physics, Tribhuvan University, Kathmandu, Nepal \\ Corresponding author: bedrajkc@yahoo.com
}

Received: May 20, $2016 \quad$ Revised: July 25, $2016 \quad$ Accepted: July 28, 2016

\begin{abstract}
The RadEst 3.00 version software estimates daily total solar radiation at low land area using meteorological parameters such as precipitation, temperatures and solar radiation of Nepalgunj (Lat.28.05 $\mathrm{N}$, Lon. $81.62^{\circ} \mathrm{E}$, and Alt.150m). Radiation is calculated as the product of the atmospheric transmissivity of radiation and radiation outside earth atmosphere. The model parameters are fitted in two years data. An accurate knowledge of solar radiation distribution in each particular geographical location is crucial for the promotion of solar active and passive energy technology. The values estimated by the models are compared with measured solar radiation data. The performance of the model was evaluated using root mean square error (RMSE), mean bias error (MBE), Coefficient of Residual Mass (CRM) and coefficient of determination $\left(\mathrm{R}^{2}\right)$. The RadEst 3.0 software which showed the better results using BC, CD, DB and DCBB, among them the DCBB model is the best model for this site. The values of RMSE, MBE, CRM and $\mathrm{R}^{2}$ are 5.20, 3.98, 0.00 and 0.47 respectively. The finding coefficients of different models can be utilized for the estimation of solar radiation at the similar meteorological sites of Nepal.
\end{abstract}

Keywords: global solar radiation, RadEst 3.00 software, precipitation, air temperature, coefficients

\section{Introduction}

Nepal is situated in between $26.37^{0}-30.45^{\circ} \mathrm{N}$ latitude and $80.07^{\circ}-88.2^{0} \mathrm{E}$ longitude so it is closer to the solar belt. The annual average global solar radiation is $3.6-6.2 \mathrm{kWh} / \mathrm{m}^{2} /$ day and the sun shines for about 300 days in a year [16]. The global solar radiation increases in altitude mainly due to decreasing amounts of air molecules, ozone, aerosols and clouds in the atmosphere. Thus there is not only the single source dependence factor [9]. The global solar radiation is an important weather variable for several environmental studies. This paper describes RadEst 3.00 software that allows the user to estimate daily global solar radiation data from maximum and minimum air temperatures and precipitation and geographical location. The best 
model can be used to relate global solar radiation, temperature and precipitation for the further study in similar geographical regions as well as for the development of solar energy technology in Nepal [15].

\section{Literature}

The non-renewable sources of energy like coal, crude oil, natural gas and uranium are being used extensively and so, the sources would be depleted to the point where it would be economically unviable to continue exploration [1]. Many scientists are worried that with large scale of consumption of fossil fuels, so they are trying to harness the Sun to use its energy for solar heating system and in sizing photovoltaic (PV) power.

A number of techniques are available for estimating solar radiation. The global solar radiation determines the energy state of the active surface and the lower atmospheric layers. The values of solar radiation determined in the first place by the Sun height and by the cloudiness. With the increase of the atmospheric haze the global solar radiation decreases especially for large sun heights. So, the annual amounts of global solar radiation are varying in larger limits [10]. This work will help the energy strategist planners to utilize the solar energy potential to solve the energy crisis of Nepal.

\section{Model}

The RadEst 3.00 software [6,7] is a MS Windows (98/NT/2000/XP program which allows evaluating daily estimation of global solar radiation values for a given latitude. These four models [2,3,4,5] (Bristow-Campbell, Campbell- Donatelli, Donatelli- Bellocchi and Modular Donatelli- Campbell -Bristow -Bellocchi (MDCBB) evaluate the results by graphical and statistical tools. The models adopt the following parameters;

$t t_{i} \quad$ estimated transmissivity,

$\tau \quad$ clear sky transmissivity,

$\Delta T \quad$ average monthly temperature $\left({ }^{\circ} \mathrm{C}\right)$,

$T_{\max } \quad$ daily maximum air temperature $\left({ }^{\circ} \mathrm{C}\right)$,

$T_{\min } \quad$ daily minimum air temperature $\left({ }^{\circ} \mathrm{C}\right)$,

$b \quad$ empirical parameter which is the temperature range coefficient or multiplier for $\Delta T$

$c \quad$ empirical parameter which is very sensitive, i.e. a small change in $c$ causes large change in estimated solar radiation

$T_{n c} \quad$ empirical parameter which is the summer night temperature factor,

$c_{1} \quad$ parameter for seasonal variation magnitude,

$c_{2} \quad$ parameter for seasonal variation profile,

$i \quad$ or $D O Y$ day of the year, $\mathrm{i}=1$ to 365 or 366

$f\left(T_{\text {avg }}\right) \quad$ function of average temperature,

$f\left(T_{\min }\right) \quad$ function of minimum temperature.

$\mathrm{Es}_{\mathrm{t}} \mathrm{Rad}_{\mathrm{i}} \quad$ estimated radiation $\left(\mathrm{MJ} \mathrm{m}^{-2}\right.$ day $\left.^{-1}\right)$ 
PotRad $_{i}$ Potential radiation outside the atmosphere $\left(\mathrm{MJ} \mathrm{m}^{-2}\right.$ day $\left.^{-1}\right)$

There are four models which estimate the atmospheric transmissivity of solar radiation based on the difference between maximum and minimum air temperature. The estimated value of radiation $\left(E s t \operatorname{Rad}_{\mathrm{i}}\right)$ is calculated as the product between the estimated transmissivity $\left(\mathrm{tt}_{\mathrm{i}}\right)$ and the value of potential radiation $\left(\operatorname{Pot} \mathrm{Rad}_{\mathrm{i}}\right.$ ) outside the earth atmosphere:

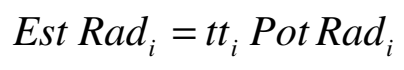

The potential radiation is estimated as

$$
\text { Pot } \operatorname{Rad}_{\text {doy }}=117.5 d d 2\left\{h_{s} \operatorname{Sin}(\text { lat }) \operatorname{Sin}(\text { dec })+\operatorname{Cos}(\text { lat }) \operatorname{Sin}\left(h_{s}\right)\right\} / \pi
$$

In this equation lat means latitude of the monitoring site, measured in degree, dec is solar declination, $\mathrm{dd} 2$ is distance of sun, $\mathrm{h}_{\mathrm{s}}$ is half day length and they are calculated using the following relations

$$
\begin{aligned}
& (d d 2)=1+0.0334 \operatorname{Cos}(0.01721 \text { day }-0.0552) \\
& h_{s}=\text { half day length }=\operatorname{Cos}^{-1}\{-\operatorname{Tan}(\text { dec }) \text { Tan }(\text { lat })\} \\
& \text { dec }=\operatorname{Sin}^{-1}[0.39785 \operatorname{Sin}\{4.869+0.0172 \text { doy }+0.03345 \operatorname{Sin}(6.224+0.0172 \text { doy })\}]
\end{aligned}
$$

\subsection{Bristow and Campbell (BC, 1984) Model}

This is the first model [2] used to derive and develop the other more models. This model exploits the relationship between diurnal air temperature range and global solar radiation load to estimate the daily radiation flux of incoming solar radiation. It assumes that daily maximum air temperature will decreases with reduction in transmissivity. Then, the minimum air temperature will increase due to the cloud emissivity. Conversely, clear skies will increase maximum air temperature due to higher short wave radiation input and minimum air temperature due to higher transmissivity. This idea has been used in numerous studies and improvements have been made over the last years [15].

$$
\text { The estimated transmissivity is } t t_{i}=\tau\left[1-\exp \left(\frac{-b \Delta \mathrm{T}_{i}^{c}}{\text { month } \Delta T}\right)\right]
$$

Hence from equation (2.34) estimated radiation provided by

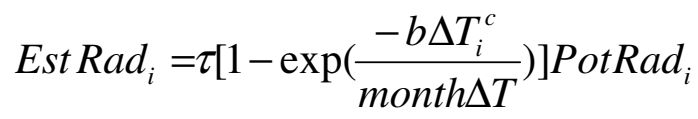

where, $\Delta T_{i}=T_{\max i}-\left(T_{\min _{i}}+T_{\min (i+j)}\right) / 2$

\subsection{Campbell and Donatelli(CD, 1998) Model}

This model [4] is derived from the modification of BC model in 1998. This model uses a correction factor accounting for seasonality effects which occur in mid-latitude areas such as Nepal. To avoid underestimation of solar radiation in summer. An estimate for transmissivity is 
increased by a factor $\mathrm{T}_{\mathrm{nc}}$ which is summer night temperature factor [8]. In this model transitivity is obtained as

$$
t t_{i}=\tau\left[1-\exp \left\{-b f\left(T_{a v g}\right) \Delta T_{i}^{2} f\left(T_{\min }\right\}\right]\right.
$$

Thus,

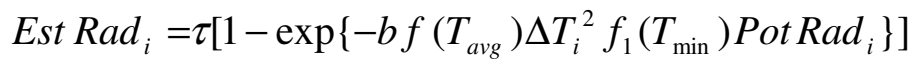

$$
\begin{aligned}
& T_{\text {avg }}=\left(T_{\max i}+T_{\min i}\right) / 2
\end{aligned}
$$

\subsection{Donatelli and Bellocchi (DB, 2001) Model}

This is the third model, [5] which takes into account of temperature fluctuation to estimate the solar radiation profile. However, it differs from the previous models. In DB the effect of the seasonal variation of the clear sky transmissivity is accounted. The temperature difference is estimated using a trigonometric function through additional parameters $c_{1}$ and $c_{2}$, general seasonality factors. The transmissivity in DB model is obtained as,

$$
t t_{i}=\tau[1+f(i)]\left[1-\exp \left\{\frac{-b \Delta T^{2}}{\Delta T_{\text {week }}}\right\}\right]
$$

Providing radiation estimate as

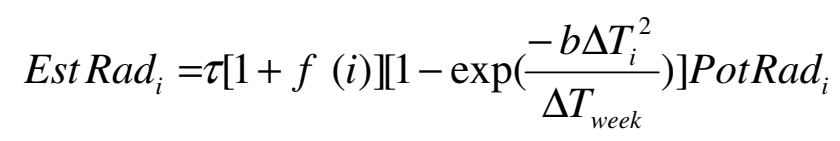

Where, $f(i)=c_{1}\left\{\operatorname{Sin}\left(i c_{2} \frac{\pi}{180}\right)+\operatorname{Cos}\left(i f\left(c_{2}\right) \frac{\pi}{180}\right)\right\}$,

$f\left(c_{2}\right)=1-1.90 c_{3}+3.83 c_{3}^{2}$,

$c_{3}=c_{2}-$ integer $\left(c_{2}\right)$,

\subsection{Donatelli-Campbell -Bristow-Bellocchi Model}

This model [6] is fourth model based on air temperature fluctuation data. It includes all the above three models allowing to switch such features. More specifically, for instance, setting parameter $\mathrm{c}_{1}=0$. Unchecking $\mathrm{T}_{\mathrm{nc}}$, and selecting the option box average monthly $\Delta \mathrm{T}$, the DCBB model becomes BC model.

The estimated transmittivity is

$$
t t_{i}=\tau[1+f(i)]\left[1-\exp \left\{\frac{-b \Delta T^{2} f\left(T_{\min }\right)}{\Delta T_{\text {avg }}}\right\}\right]
$$

which provides radiation estimate as 


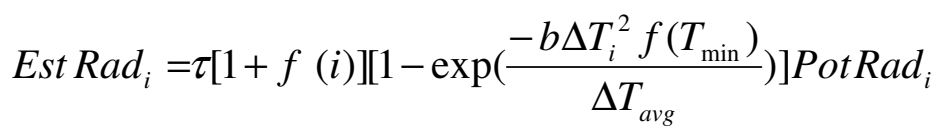

where, $f(i)=c_{1}\left\{\operatorname{Sin}\left(i c_{2} \frac{\pi}{180}\right)+\operatorname{Cos}\left(i f\left(c_{2}\right) \frac{\pi}{180}\right)\right\}$

$f\left(c_{2}\right)=1-1.90 c_{3}+3.83 c_{3}^{2}$

$f\left(T_{\text {avg }}\right)=0.017 \exp \left\{\exp \left(-0.053 x T_{\text {avg }}\right)\right\}$,

where, $T_{\text {avg }}=\left(T_{\max i}+T_{\min i}\right) / 2$ and $f\left(T_{\min }\right)=\exp \left(T_{\min } / T_{n c}\right)$,

$$
c_{3}=c_{2} \text {-integer }\left(c_{2}\right)
$$

\section{Methods and Materials}

\subsection{Instrumentation and Data Format}

Environmental data were collected by the Environ data Weather Master 2000 (WM 20) instrument installed at Department of Hydrology and Meteorology Nepalganj Airport, (Lat. $28.05^{\circ} \mathrm{N}$, Lon. $81.62^{\circ} \mathrm{E}$, and Alt.150m). This device is a compact, robust and automatic weather station. It consists of six electronic weather sensors, which measure the air temperature in the range from $-15^{\circ} \mathrm{C}$ to $+60^{\circ} \mathrm{C}$ (accuracy $\pm 0.2^{\circ} \mathrm{C}$ at $25^{\circ} \mathrm{C}$, resolution $0.1^{0} \mathrm{C}$ ), relative humidity capacitance type (accuracy $\pm 3 \%$ in the range $0-90 \%$ and $\pm 4 \%$ in the range $90 \%-100 \%$ ), rainfalltipping bucket mechanism $(0.2 \mathrm{~mm}$ resolution), wind speed (3 cup $66 \mathrm{~mm}$ anemometer rating $70 \mathrm{~m} / \mathrm{s}$, resolution $0.1 \mathrm{kph}$ ) and wind direction-hall effect sensing (resolution 2 degrees, accuracy $\pm 2^{0}$ ) and solar radiation (cosine correction accuracy $\pm 5 \%$, cosine corrected $\pm 3 \%$ ), respectively. It has Easy-Access Windows database and reporting sophisticated software, automatic evaporation calculation, internal data logger and battery, solar panel and powder-coated stand.

Each sensor continuously sends information to the data logger, which processes and stores the data in its memory. In addition, one optional sensor can be connected up to $100 \mathrm{~m}$ away to allow the WM 20 to be customized to suit user application. This does, however, reduce the storage of 15 minutes (for 20 days), hourly (for 65 days) and daily (for 100 days). All the measuring data are recorded by data stored into 4 independent memory areas. 104K battery backed RAM stores a total of 29,00 data readings within 15 minutes interval for 24 hours. It features low noise, high resolution and low power consumption. It can be used in all weather conditions. It collects the data at real time for the needs of meteorology and slow signal analysis.

A serial RS232C connection allows to transfer data to a PC. Easy-Access is an integrated package that includes data collection, storage and display modules. In addition, software failure as a result of nearby lighting strike initiates an automatic circuit 'watch dog' to restart the logger within seconds, ensuring data storage is uninterrupted. The performance of sensors of instrument is excellent because of their accuracy level, correction factor and high resolution [11]. The 
measured data of global solar radiation and meteorological parameters are utilized in the RadEst 3.0 ver. Software. Its explanation is given above.

All these models take into account of daily precipitation, maximum and minimum temperature and total solar radiation i.e. (DOY, Rain, Tmax, Tmin, Rad) data of each year without headers in ASCII format. It means that all models should arrange the data day of one year (from 1 to 365), rainfall $(\mathrm{mm})$, maximum temperature Tmax $(0 \mathrm{C})$, minimum temperature Tmin $(0 \mathrm{C})$ and global solar radiation in $\mathrm{Rad}(\mathrm{MJ} / \mathrm{m} 2 /$ day). The daily values of global solar radiation have been estimated for two years (2011 and 2013) of input data of Nepalgunj.

\subsection{Input Format}

In the RadEst 3.00 version software, it is necessary to input the latitude, longitude and altitude of the monitoring locations for four models. In spite of this, the clear sky transmissivity ranges from $0.60-0.80$ is selected. The latitude is explicitly used in the expression of potential radiation and clear sky transmissivity is used in the expression of transmissivity coefficient of atmospheric radiation in each model. It is also used in the calculation of global solar radiation and its plot.

\subsection{Analysis}

First of all the data is carried out using auto optimization (AO) and parameter fitting (PF) whereas at least 2 years data is required for the comparison as well as estimation of global solar radiation. AO can be less accurate method as compared to PF. Thus AO has no significant effect so it is not considered in this analysis. PF is more convenient because of key parameters which are directly related to the affecting factors of solar radiation. It is used by varying the different parameters to get closer value in between estimated and measured radiation. After the analysis the different models give the value of root mean square error (RMSE), coefficient of residual mass (CRM), mean bias error (MBE) and coefficient of determination $\left(\mathrm{R}^{2}\right)$. Those tools help to justify the model estimated value and measured value of radiation.

\section{Results and Discussions}

All four models were calibrated using parameter fitting (PF) on the basis of 2011data of Nepalgunj by minimizing Coefficient of Residual Mass (CRM), MBE and RMSE should be smaller as for as possible or nearly equal zero. The value of $\mathrm{R}^{2}$ should be greater as far as possible. Finally the equal values of measured and model estimated radiation are found in PF in 2011. The finding value of model estimated and measured global solar radiation value $12.9 \mathrm{MJ} / \mathrm{m}^{2}$ is found. Measured and Model estimated average value, maximum value and yearly total Value of Global solar Radiation of Nepalgunj 2011 is given in Table 1. The Table 1 data shows that there is nearly closer value are found in DCBB model to compare in $\mathrm{BC}, \mathrm{CD}$ and $\mathrm{DB}$ hence DCBB is better model in 2011 for the estimation of global solar radiation. 
Table 1: Measured and Model estimated Average Value, Maximum Value and Yearly total Value of Global solar Radiation of Nepalgunj 2011

\begin{tabular}{|c|c|c|c|c|c|c|}
\hline \multirow{2}{*}{ Models } & \multicolumn{2}{|c|}{$\begin{array}{c}\text { Average Value } \\
\left(\mathrm{MJ} / \mathrm{m}^{2}\right)\end{array}$} & \multicolumn{2}{c|}{$\begin{array}{c}\text { Maximum value } \\
\left(\mathrm{MJ} / \mathrm{m}^{2}\right)\end{array}$} & \multicolumn{2}{c|}{$\begin{array}{c}\text { Yearly total } \\
\left(\mathrm{MJ} / \mathrm{m}^{2}\right)\end{array}$} \\
\cline { 2 - 7 } & MEA & EST & MEA & EST & MEA & EST \\
\hline BC & 12.9 & 12.9 & 23.5 & 25.1 & 4712 & 4722 \\
\hline CD & 12.9 & 12.9 & 23.5 & 26.1 & 4712 & 4703 \\
\hline DB & 12.9 & 12.9 & 23.5 & 24.7 & 4712 & 4725 \\
\hline MDCBB & 12.9 & 12.9 & 23.5 & 26.0 & 4712 & 4718 \\
\hline
\end{tabular}

The calibrated values of the parameters from 2011 are used to estimate the global radiation for the year 2013 data. First of all, the all four models are tested by auto optimize result and the estimated values are highly deviate with measured value of GSR. Similarly the parameter fitting method is used to estimate the GSR then it is found that the estimated value of GSR is very close to the measured value of global solar radiation. The PF based testing values is given in Table 2 .

Table 2: Measured and Model estimated Average Value, Maximum Value and Yearly total Value of Global solar Radiation of Nepalgunj 2013

\begin{tabular}{|l|c|c|c|c|c|c|}
\hline \multirow{2}{*}{ Models } & \multicolumn{2}{|l|}{$\begin{array}{l}\text { Average Value } \\
\left(\mathrm{MJ} / \mathrm{m}^{2}\right)\end{array}$} & \multicolumn{2}{l|}{$\begin{array}{l}\text { Maximum value } \\
\left(\mathrm{MJ} / \mathrm{m}^{2}\right)\end{array}$} & \multicolumn{2}{l|}{$\begin{array}{l}\text { Yearly total } \\
\left(\mathrm{MJ} / \mathrm{m}^{2}\right)\end{array}$} \\
\cline { 2 - 7 } & MEA & EST & MEA & EST & MEA & EST \\
\hline BC & 12.9 & 12.4 & 33.2 & 25.1 & 5639 & 4668 \\
\hline CD & 12.9 & 12.6 & 33.2 & 26.7 & 4699 & 4611 \\
\hline DB & 12.9 & 12.12 & 33.2 & 24.5 & 4699 & 4676 \\
\hline MDCBB & 12.9 & 12.8 & 33.2 & 25.8 & 4699 & 4677 \\
\hline
\end{tabular}

Table 2, data shows that the measured and model estimated average Value, maximum value and yearly total value of global solar Radiation of model DCBB tentatively equal is found in DCBB model in comparison of the other 3 models BC, CD and DB thus the model DCBB is the best among other three models to estimate the global solar radiation in this low land region of Nepal in 2013.

Error Analysis of Years 2011 and 2013 data: Table 3 shows the error analysis in between measured and model estimated data the of global solar radiation in 2011. In 2011 the RMSE is lower in DCBB model than BC however most of the values of MBE, and CRM are lower to compare the $\mathrm{BC}$ model and the value of $\mathrm{R}^{2}$ is also greater in DCBB than $\mathrm{BC}$ model thus it is confirmed that among the four models the DCBB is the best in terms of statistical analysis. 
206 Estimation of the Daily Global Solar Radiation using RadEst 3.00 Software at Nepalgunj, Nepal

Table 3: Error Analysis of Year 2011

\begin{tabular}{|c|c|c|c|c|}
\hline Models & $\begin{array}{c}\text { RMSE } \\
\left(\mathrm{MJ} / \mathrm{m}^{2}\right)\end{array}$ & $\begin{array}{c}\text { MBE } \\
\left(\mathrm{MJ} / \mathrm{m}^{2}\right)\end{array}$ & $\begin{array}{c}\mathrm{CRM} \\
(\text { Unitless })\end{array}$ & $\begin{array}{c}\mathrm{R}^{2} \\
(\text { Unitless })\end{array}$ \\
\hline $\mathrm{BC}$ & 5.23 & 4.09 & 0.00 & 0.44 \\
\hline $\mathrm{CD}$ & 5.71 & 4.41 & 0.00 & 0.43 \\
\hline $\mathrm{DB}$ & 4.98 & 3.86 & 0.00 & 0.46 \\
\hline MDCBB & 5.2 & 3.98 & 0.00 & 0.47 \\
\hline
\end{tabular}

Table 4 shows the error analysis in between model estimated and measured value of global solar radiation of 2013. It is found that most of the values of RMSE, MBE and CRM are comparatively lower in DCBB than $\mathrm{BC}, \mathrm{CD}$ and $\mathrm{DB}$ models and the value of $\mathrm{R}^{2}$ is higher in DCBB than other three remaining models. It concluded that DCBB model proved the best fit among the other three models.

Table 4: Error Analysis of Year 2013

\begin{tabular}{|c|c|c|c|c|}
\hline Models & RMSE(MJ/m $\left.{ }^{2}\right)$ & $\operatorname{MBE}\left(\mathrm{MJ} / \mathrm{m}^{2}\right)$ & $\begin{array}{c}\mathrm{CRM} \\
(\text { No Unit })\end{array}$ & $\begin{array}{c}\mathrm{R}^{2} \\
(\text { No Unit })\end{array}$ \\
\hline $\mathrm{BC}$ & 5.22 & 3.95 & 0.01 & 0.42 \\
\hline $\mathrm{CD}$ & 5.53 & 4.2 & 0.02 & 0.41 \\
\hline $\mathrm{DB}$ & 5.01 & 3.72 & 0.00 & 0.43 \\
\hline $\mathrm{MDCBB}$ & 5.28 & 3.94 & 0.00 & 0.46 \\
\hline
\end{tabular}

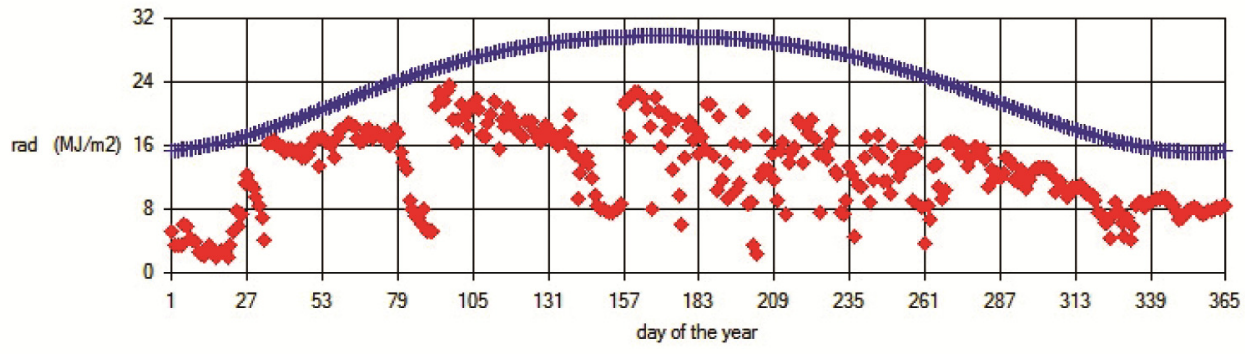

Fig. 1 (top) and 2 (bottom): The variation of daily global solar radiation in 2011 and 2013

The Fig. 1 and 2 show that the variation of global solar radiation with day of the year. The radiation varies significantly due to high concentration of moisture and local weather condition. The average measured values of GSR are about $12.9 \mathrm{MJ} / \mathrm{m} 2 /$ day and $12.8 \mathrm{MJ} / \mathrm{m} 2 /$ day in 2011 and 2013 respectively at Nepalgunj. Similarly there is lacking of measured data of solar radiation in 2011 after 273 day number. Thus there is more error is found in RMSE and MBE values in 2011 than in 2013 data of RMSE and MBE. It is clearly shown in table 3 and 4. 
Fig. 3 and 4 show that coefficient of determination in between estimated value and measured value of solar radiation of 4 models, the DCBB Model is the best because .most of the data are very close to the correlation line with higher value of $\mathrm{R}^{2}$ in 2013 data of Nepalgunj.
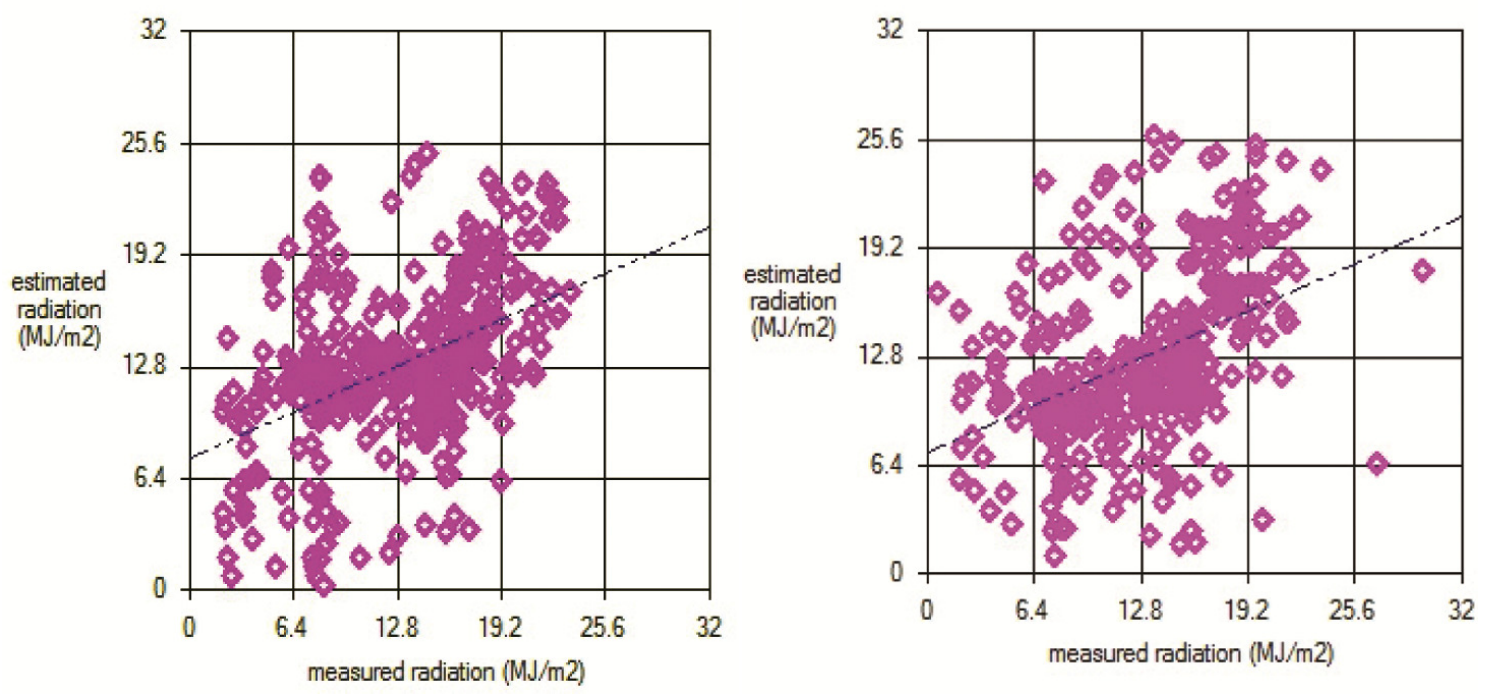

Fig. 3 (left) and 4 (right): The coefficient of determination in between estimated value and measured value of solar radiation in 2011and 2013 of DCBB model

Fig. 3 and 4 show that there is 0.22 and 0.19 coefficient of determination is found in 2011 and 2013. These values are the maximum in DCBB model in comparison with other three BC, CD and DB models.
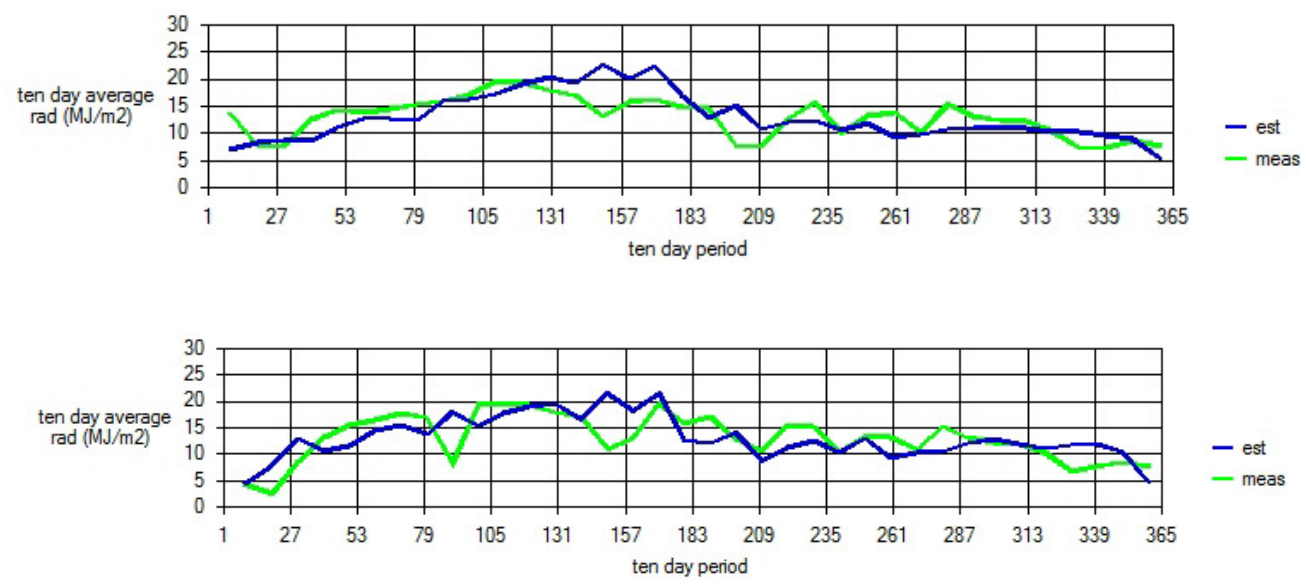

Fig. 5 (top) and Fig. 6 (bottom): The comparative study of ten days average value of estimated and measured radiation with ten day period in 2011 (top) and in 2013 (bottom). 
Fig. 5 indicates that there is mostly leading the estimated values of global solar radiation to the measured values of radiation up to the 224 day number in 2011. However there is missing the measured data after the 273 days. From the 209day number the measured values of radiation leads to the estimated data because of local weather condition. Similarly, Fig. 6 shows that there is tentatively the estimated values of radiation leads by the measured data up to the 183 day number after that the measured data dominates the estimated value of solar radiation . It is happened due to the local weather condition such as humidity, clouds, wind direction etc.

Table 5 shows the comparative study of finding calibrated model coefficients of Nepalgunj Nepal. These data can be utilized to the similar meteorological locations of Nepal.

Table 5: Calibrated Model coefficients for different locations of the world[13]

\begin{tabular}{|c|c|c|c|c|c|c|}
\hline S.N. & Models & $\begin{array}{l}\text { Parameter } \\
\text { s }\end{array}$ & $\begin{array}{l}\text { Cortez Colorado } \\
\text { (USA) }\end{array}$ & Padova(Italy) & $\begin{array}{l}\text { Rothamsted } \\
\text { (UK) }\end{array}$ & $\begin{array}{l}\text { Nepalgunj } \\
\text { (Nepal) }\end{array}$ \\
\hline $\mathbf{1 .}$ & BC & B & 0.17 & 0.141 & 0.110 & 0.061 \\
\hline & & C & 2 & 2 & 2 & 2 \\
\hline $\mathbf{2 .}$ & CD & B & 0.203 & 0.396 & 0.345 & 0.259 \\
\hline & & Tnc & 104.1 & 42.1 & 106.1 & 47.5 \\
\hline $\mathbf{3 .}$ & DB & B & 0.112 & 0.131 & 0.106 & 0.103 \\
\hline & & C1 & 0.034 & -0.040 & -0.011 & -0.02 \\
\hline & & C2 & 1.410 & 0.008 & 1.183 & 1.365 \\
\hline $\mathbf{4 .}$ & DCBB & B & NA & NA & NA & 0.085 \\
\hline & & C1 & NA & NA & NA & 0.054 \\
\hline & & C2 & NA & NA & NA & 0.841 \\
\hline & & Tnc & NA & NA & NA & 68.7 \\
\hline
\end{tabular}

Source: G.M. Abraha and M.J. Savage 2008., Poudyal et al. 2012, 2015[14]

\section{Conclusion}

It is concluded that these four models Bristow-Campbell, Campbell- Donatelli, Donatelli Bellocchi and Modular DCBB used to estimate the global solar radiation varying with key parameters and testing by graphical and statistical tools on 2011 and 2013 at Nepalgunj. Finally the overall performance of the model was evaluated by statistical tools such as root mean square error (RMSE), mean bias error (MBE), Coefficient of Residual Mass (CRM) and coefficient of determination $\left(\mathrm{R}^{2}\right)$. Finally, it is confirmed that the Modular DCBB is the best model for this location for estimation of global solar radiation at Nepalgunj and other similar meteorological 
sites of Nepal. The finding coefficients can be utilized to estimate the global solar radiation at the similar meteorological sites of Nepal.

\section{Acknowledgment}

Authors are grateful to Department of Hydrology and Meteorology (DHM), Government of Nepal for providing all necessary meteorological data. We are thankful to NAST for installing Pyranometer in M.M. Campus, T.U., Nepalgunj for measurement of Solar radiation. Authors are grateful to FAO-SDRN Agrometerology Group, Rome, Italy and ISCI-Crop Science, Bologna, Italy for providing free version of RadEst 3.00 software and manual through website.

\section{References}

[1] Augustine C and Nnabuchi MN (2009), Relationship between global solar radiation and sunshine hours for Calabar, Port Harcourt and Enugu, Nigeria. J. Physical Sciences 4(4) : 182188.

[2] Bristow KL and Campbell GS (1984), On the relationship between incoming solar radiation and daily maximum and minimum temperature. Agric. For. Meterol. 31: 159-166

[3] Chegaar M, Lamri A and Chibani A (1998), Estimating Global Solar Radiation Using Sunshine Hours. P. Energetique 7-11.

[4] Donatelli M and Bellocchi GS (1998), A simple model to estimate global solar radiation In: proceedings of the fifth congress of the European Society for Agronomy Nitra, Slovakia, II, 133-134.

[5] Donatelli M and Bellocchi GS (2001), Estimates of Daily Global Solar Radiation: New developments in the software RadEst3.00. 213-214. In: Proc. Int. Symp. Modelling Cropping Syst., 2nd, Florence, Italy, 16-18 2001. Inst. for CNR, Florence, Italy.

[6] http://www.isci.it/tools

[7] http://www.sipeaa.it/tools

[8] Bechini L, Duccob G, Donatelli M and Stein (2000), Agric. Eco. Environ. 81: 29-42.

[9] Poudyal KN, Daponte P, Vito LD, Bhattarai BK and Sapkota B (2010), Proc. of XVII IMEKO TC-4 Int. Symposium, Kosice, Slovak Rep.

[10] Liou KN (1980), An Introduction to Atmospheric Radiation, Academic press, New York.

[11] Manual, (1982), Envirodata Environmental Monitoring and Management EasiData Mark 4, Queensland, 4370, Australia,

[12] Donatelli M and Bellocchi GS (2001), Cropping Systems, Italy, p. 213.

[13] Murray and Larry J (2004), Theory and Problem of Statistics, 3rd edition, Schaum's series

[14] Poudyal KN, Bhattarai BK, Sapkota B and Kjeldstad B (2012), Estimation of Global Solar Radiation using Sunshine Duration in Himalaya Region, J. Chemical Sciences 2(11) : 20-25.

[15] McVicar TR and Jupp DLB, Agric (1999), For. Meteorol., 96 : 219-238.

[16] Water and Energy Commission Secretariat (WECS), Energy Sector Synopsis Report Nepal, 2010. 